\title{
PENGARUH MODEL PEMBELAJARAN SAVI (SOMATIS, AUDIOTORI, VISUAL, INTELEKTUAL) TERHADAPHASIL BELAJAR SISWA KELAS VII DALAM PEMBELAJARAN LAGU DAERAHSETEMPAT SMP PARULIAN 2 MEDAN
}

\author{
NORALISA \\ Prodi Pendidikan Musik
}

\begin{abstract}
This study aims to determine the effect of learning model SAVI (Somatic Audiotori, Visual, Intellectual Property) to the learning outcomes of students class VII SMP Parulian 2 Medan.

This study is based on a theoretical foundation to explain the learning model SAVI (Somatic Audiotori, Visual, Intellectual), learning outcomes, and Song local area, along with the hypothesis.

The research method in this study using an experimental research. This type of research is True Experimental Design with pretest design -Posttest Control Group Design. The population in the study were all students of class VIII SMP Parulian 2 field consisting of 4 classes. Sampling was done by random sampling by taking two classes, namely the class VII4 as an experimental class that numbered 30 people and VII2 class as the control class that numbered 30 people. The instrument used to determine student learning outcomes is the achievement test in the form of multiple choice numbered 30 and 20 items that have been declared valid for the experimental class and control class that has been tested on VIII class in junior Parulian 2 Medan.
\end{abstract}

The second class are given a pretest to determine the ability of the student before the beginning of the treatment given in each grade, with an average value of 38.83 experimental class and control class 35.83. then given a different treatment, the experimental class learning model SAVI (Somatic, Audiotori, Visual, Intellectual) and grade control with conventional learning (direct). After learning is completed given postes, obtained postes with an average value of 76.83 experimental class and control class 66.87. Hypothesis test results using a different test ( $t$-test) obtained $t>t$ table so $H a$ is received, so that the results showed that there was a $15.67 \%$ influence learning model SAVI (Somatic, Audiotori, Visual, Intellectual) the learning outcomes of students of class VII in Learning Locally in the Junior songs Parulian 2 Medan.

Keywords: learning model SAVI (Somatic, Audiotori, Visual, Intellectual), conventional, Songs Locally 


\section{PENDAHULUAN}

\section{A. Latar Belakang Masalah}

Perkembangan

Ilmu

Pengetahuan dan Teknologi (IPTEK) yang semakin canggih seperti sekarang ini, tentu perlu didampingi oleh pengembangan Sumber Daya Manusia (SDM) yang berkualitas. Salah satunya adalah pengembangan kualitas pendidikan karena pendidikan memegang peranan penting dalam meningkatkan dan mengembangkan kualitas Sumber Daya Manusia (SDM). Pendidikan adalah usaha sadar yang sengaja ( terkontrol, terencana dengan sadar, dan secara sistematis) diberikan kepada anak didik oleh pendidik agar anak didik dapat berkembang dan terarah pada tujuan tertentu. Seorang guru harus dituntut memiliki pemahaman tentang peserta didik, mampu mengembangkan kurikulum, merancang pembelajaran, melaksanakan pembelajaran yang mendidik, melakukan evaluasi dan mengembangkan potensi peserta didik. . Dalam proses pembelajaran dikelas, guru harus mampu menguasai kelas sehingga kelas menjadi sarana bagi siswa untuk mengembangkan setiap potensi yang ada dalam diri siswa sehingga hasil belajar siswa pun bisa semakin baik

Dalam proses belajar mengajar, hasil belajar merupakan acuan pada guru apakah pembelajaran berhasil atau tidak. Berhasil atau tidaknya proses pembelajaran tergantung bagaimana guru mampu membuat perencanaan pembelajaran semenarik mungkin. Salah satunya adalah mata pelajaran seni budaya. Salah satu pembelajaran seni budaya yang akan dibahas penulis yaitu seni musik. Dalam pembelajaran seni musik, sering kali guru masih menggunakan model pembelajaran yang 
berpusat pada guru atau sering disebutkan dengan model pembelajaran langsung (Konvensional), sehingga membuat siswa tidak termotivasi bahkan tujuan pembelajaran tidak tercapai karena materi tidak sampai kepada siswa, berdasarkan wawancara yang dilaksanakan oleh penulis dengan guru mata pelajaran seni budaya di SMP Parulian 2 Medan rata-rata siswa pada pelajaran seni budaya sangat rendah , bahkan sudah dilaksanakan remedial masih ada siswa yang mendapat nilai dibawah KKM ( Kriteria Ketuntasan Minimal). Dalam hal ini model pembelajaran yang diterapkan oleh guru tersebut kemungkinan tidak sesuai dengan kebutuhan siswa. Dalam silabus SMP kelas VII terdapat materi pelajaran seni budaya yaitu lagu daerah setempat. Lagu daerah setempat adalah lagu atau musik yang berasal dari suatu daerah tertentu dan menjadi populer dinyanyikan baik oleh rakyat daerah tersebut maupun rakyat lainnya. Bentuk lagu ini sangat sederhana dan menggunakan bahasa daerah atau bahasa setempat. Banyak siswa yang kurang suka dengan lagu daerah karena adanya jenis musik yang lebih menarik didalam dunia remaja. maka dari itu guru harus melakukan evaluasi mengenai model pembelajaran yang tepat.

Dari penjelasan diatas maka peneliti ingin mencoba membuat eksperimen dengan menggunakan model pembelajaran SAVI ( Somatis, Audiotori, Visual, Intelektual ) pada pembelajaran lagu daerah setempat. Untuk melihat apakah ada pengaruh maupun perubahan yang terjadi pada hasil belajar maupun keaktifan siswa. Apakah pengaruhnya semakin baik atau justru semakin buruk. 
Model pembelajaran SAVI

Somatis, Audiotory, Visual dan Intelektual ) sangat tepat dalam mengajarkan materi lagu daerah setempat, hal ini dikarenakan model pembelajaran SAVI ( Somatis, Audiotory, Visual, dan Intelektual ) dapat memenuhi kebutuhan gaya belajar siswa yang tidak hanya mendengarkan penjelasan dari guru, melainkan juga dapat melihat langsung contoh konkret penjelasan guru tersebut bahkan dapat ikut serta aktif didalam kelas. Dalam materi pembelajaran Lagu daerah Setempat, guru tidak hanya menjelaskan mengenai materi tersebut tetapi guru dapat pula memperdengarkan contohcontoh lagu daerah sehingga siswa lebih mudah memahami penjelasan dari guru dan dapat mengerjakan apa yang akan ditugaskan oleh guru.

Berdasarkan uraian diatas, ada permasalahan yang menarik untuk diteliti yaitu bagaimana pengaruh Model pembelajaran SAVI ( Somatis, Audiotori, Visual, dan Intelektual ) terhadap hasil belajar siswa di SMP Parulian 2 Medan. Oleh karena itu, penulis tertarik untuk meneliti “ Pengaruh Model Pembelajaran SAVI ( Somatis, Auddiotoru, Visual, dan Intelektual ) Terhadap Hasil Belajar Siswa Kelas VII Dalam Pembelajaran Lagu Daerah Setempat SMP Parulian 2 Medan”.

\section{B. Tujuan Penelitian}

1. Untuk mengetahui pengaruh model pembelajaran SAVI ( Somatis, Audiotori, Visual, Intelektual ) terhadap hasil belajar kelas VII dalam pembelajaran lagu daerah setempat SMP Parulian 2 Medan.

2. Untuk memgetahui hasil belajar siswa kelas VII dalam pembelajaran lagu daerah setempat dengan 
menggunakan model pembelajaran langsung (konvensional)

3. Untuk mengetahui hasil belajar siswa kelas VII dalam pembelajaran lagu daerah setempat setelah diterapkannya model pembelajaran SAVI ( Somatis, Ausiotori, Visual, Intelektual ).

\section{Landasan Teoritis}

Setelah masalah yang dirumuskan, maka langkah selanjutnya adalah mencari teori-teori yang mendukung penelitian karena setiap penelitian tentunya harus berlandaskan teori-teori yang akan dijadikan sebagai landasan teori. Sitirahayu ( dalam Sugiyono, 2013: 80 ) menyatakan bahwa " suatu teori akan memperoleh arti yang penting, bila ia lebih banyak dapat melukiskan, menerangkan, dan meramalkan gejala yang ada". melihat bahwa kajian teoritis sangat penting untuk sebuah penelitian agar penelitian yang dilakukan berdasarkan oleh teoriteori yang sudah teruji kebenarannya. Dengan pengembangan teori-teori yang akan diangkat dari analisis kepustakaan, diharapkan mendukung pikiran penulis apalagi didukung oleh fakta-fakta yang ada, sehingga penelitian ini dapat menghasilkan kesimpulan yang didasarkan pada tujuan yang telah dibuat.

\section{A. Lokasi dan Waktu Penelitian}

\section{Lokasi Penelitian}

Sesuai dengan judul penelitian “ Pengaruh Model Pembelajaran SAVI ( Somatis, Audiotori, Visual, Intelektual ) terhadap hasil belajar siswa kelas VII dalam Pembelajaran Lagu Daerah Setempat SMP Parulian 2 Medan Jl. Garuda Raya Perumnas Mandala. 


\section{Waktu Penelitian}

Waktu penelitian ini akan

dilakukan pada bulan Januari sampai Maret 2017.

\section{B. Populasi dan Sampel}

\section{Populasi}

Yang menjadi populasi dalam penelitian ini adalah seluruh siswa kelas

VII SMP Parulian 2 Medan yang berjumlah 147 orang.

\section{Sampel}

Penulis menentukan kelas $\mathrm{VII}_{4}$ sebagai kelas eksperimen yang menggunakan model pembelajaran SAVI ( Somatis, Audiotori, Visual, Intelektual ) dan kelas $\mathrm{VII}_{2}$ sebagai kelas kontrol yang menggunakan model pembelajaran Konvesional ( langsung) yang berpusat pada guru.

\section{Variabel Penelitian}

\section{Variabel Independen $(\mathrm{X})$}

variabel independen (bebas)

penelitian ini adalah model pembelajaran SAVI (Somatis, Audiotori, Visual, Intelektual) yaitu pembelajaran yang menekankan bahwa belajar haruslah menggunakan memanfaatkan semua alat indra yang dimiliki siswa.

\section{Variabel Bebas (Y)}

$$
\text { variabel dependen ( terikat) }
$$
dalam penelitian ini adalah Hasil belajar siswa pada materi belajar lagu daerah setempat.

D. Teknik Pengumpulan Data dan Instrumen Penelitian

\section{Instrumen Tes Hasil Belajar}

Dalam bidang pendidikan instrumen penelitian yang digunakan 
sering disusun sendiri termaksud menguji validitasnya. Untuk memperoleh data yang valid dalam penelitian ini, maka instrumen penelitian yang digunakan yaitu dengan tes.

\section{Kisi-kisi Instrumen}

Data dalam penelitian ini termaksud data kuantitatif yaitu berupa hasil belajar siswa pada materi Lagu daerah setempat. Untuk memperoleh data tersebut digunakan tes hasil belajar, tes hasil belajar yang digunakan adalah pilihan ganda yang mempunyai 4 pilihan yaitu a, b, c, dan d untuk pretest maupun post-test.

\section{Uji Coba Instrumen}

Uji coba instrument dimaksud untuk menentukan apakah suatu butir instrument (1) telah memenuhi syarat untuk digunakan dalam pengukuran/penelitian. (2) apakah butir instrument tersebut harus diperbaiki karena terbukti masih memiliki beberapa kelemahan, atau (3) apakah butir tes tersebut harus digugurkan/tidak digunakan sama sekali karena terbukti tidak berfungsi. Karena kaakteristik yang harus dianalisis dari instrument adalah : (1) tingkat kesukaran, (2) daya pembeda, (3) Validitas, distruktor/pengecoh dan reliabilitas.

\section{E. Teknik Analisi Data}

\section{Uji Normalitas}

Uji normalitas data digunakan uji lilefors sebagai berikut :

1. Pengamatan $\mathrm{X}_{1}, \mathrm{X}_{2}$ ............. $\mathrm{X}_{\mathrm{n}} \quad$ dijadikan bilangan baku $\mathrm{Z}_{1}, \mathrm{Z}_{2}$, sampai $\mathrm{Z}_{\mathrm{n}}$, dengan rumus :

$$
Z_{i}=\frac{x_{i}-\bar{x}}{s}
$$


Keterangan :

$$
\begin{array}{ll}
\bar{X} & =\text { Nilai rata-rata } \\
\mathrm{S} & =\text { Simpangan }
\end{array}
$$

Baku

2. Untuk setiap angka baku ini menggunakan distribusi normal baku, kemudian dihitung peluang dengan $\mathrm{F}$ $\left(\mathrm{Z}_{\mathrm{i}}\right)=\mathrm{P}\left(\mathrm{Z} \leq Z_{i}\right)$

3. Selanjutnya menghitung proporsi $\mathrm{S}(\mathrm{Zi})$ dengan rumus

$$
\mathbf{S}\left(\mathbf{Z}_{\mathbf{i}}\right)=
$$

$\frac{\text { Banyaknya } z_{1}, z_{2} \ldots \ldots \ldots \ldots z_{n \leq z_{i}}}{N}$

4. Menghitung selisih $\mathrm{F}(\mathrm{Zi})-$ $\mathrm{S}(\mathrm{Zi})$ kemudian ditentukan harga mutlaknya.

5. Mengambil harga yang paling besar duantara harga -harga mutlak selisih tersebut, sebut namanya L hitung dengan harga $\mathrm{L}$ tabel

$$
(a=0.05)
$$

6. Jika L hitung $<\mathrm{L}$ tabel berarti data berdistribusi normal dan jika sebaliknya maka sampel tidak berdistribusi normal.

\section{Uji Homogenitas}

Untuk menghitung homogenitas digunakan rumus :

$$
\begin{aligned}
& \mathrm{F}= \\
& \frac{\text { Varians terbesar }}{\text { varians terkecil }} \text { atau } F= \\
& \frac{s_{1}^{2}}{s_{2}^{2}}
\end{aligned}
$$

Keterangan :

$s_{1}^{2}$ Varians dari kelompok lebih besar

$s_{2}^{2} \quad=$ Varians dari kelompok lebih kecil

Kriteria pengujian : jika $F_{\text {hitung }} \leq$ $\mathrm{F}_{\text {tabel }}$, maka Ho diterima ( homogen ).

\section{Uji Hipotesis}

Pengujian hipotesis dilakukan dengan cara uji kesamaan rata-rata postest (uji t satu pihak ). Uji t satu pihak digunakan untuk mengetahui adanya peningkatan hasil belajar siswa 
dilihat dari ada tidaknya perbedaan hasil postes siswa pada kedua kelas yaitu kelas eksperimen dan kelas kontrol.

$$
\begin{aligned}
& H_{o}: \mu_{S T} \leq \mu_{E} \\
& H_{a}: \mu_{S T}>\mu_{E}
\end{aligned}
$$

\section{HASIL PENELITIAN DAN} PEMBAHASAN

\section{A. HASIL PENELITIAN}

\section{Analisis Instrumen Penelitian}

Pada bagian ini akan diuraikan secara terperinci mengenai hasil dari penelitian tentang pengaruh model pembelajaran SAVI (Somatis, Audiotori, Visual, Intelektual) terhadap hasil belajar siswa pada materi lagu daerah setempat kelas VII SMP Parulian 2 Medan Tahun Pembelajaran 2016/2017. Penelitian ini dilakukan pada dua kelas yang berbeda, dimana kelass $\mathrm{VII}_{4}$ dengan menggunakan model pembelajaran SAVI (Somatis, Audiotori, Visual, Intelektual) dan kelas $\mathrm{VII}_{2}$ dengan menggunakan model pembelajaran konvensional. Sebelum data ini diperoleh instrumen penelitian terlebih dahulu di uji coba ke kelas VII di sekolah SMP Parulian 2 Medan, untuk melihat validitas, reabilitas, tingkat kesukaran soal, dan daya beda soal, melalui hasil tes tersebut diperoleh gambaran sebagai berikut :

\section{a. Uji Validitas}

Uji validitas dilakukan sebelum memberikan perlakuan pada 2 kelas yaitu kelas eksperimen dan kelas kontrol. Soal untuk validitas adalah soal pilihan berganda dengan jumlah soal sebanyak 30 soal yang mewakili setiap indikator. Tes yang telah disusun di uji cobakan kepada 34 siswa kelas $\mathrm{VII}_{1}$ SMP Parulian 2 Medan. Dari 30 soal yang diuji cobakan terdapat 20 soal yang valid dan 10 soal yang tidak valid. 


\section{b. Uji Reabilitas}

untuk uji reabilitas jika $r_{\text {hit }}>r_{\text {tab }}$ maka soal tersebut dikatan reliabel. Dari hasil data yang diperoleh $r_{\text {hit }}=0,891$ sedangkan $r_{\text {tab }}=0,334$, sehingga dapat disimpulkan bahwa soal tersebut secara keseluruhan memiliki reabilitas yang tinggi untuk mengukur hasil beljar siswa.

\section{c. Tingkat kesukaran Tes}

Setiap soal memiliki krieteria, sukar, sedang, mudah. Jika ketiga kategori ini sudah ada dalam soal maka soal tersebut merupakan soal yang layak untuk digukanan. Berdasarkan perhitungan dari tingkat kesukaran tes maka terdapat 30 soal yang diujikan, terdapat 5 butir soal sukar, 15 butir soal sedang, 4 soal mudah dan 6 soal sangat mudah.

\section{d. Uji Daya Beda Tes}

Berdasarkan perhitungan uji daya beda tes maka diperoleh hasil dengan daya beda baik sebanyak 7 soal, daya beda cukup sebanyak 14 soal, daya beda jelek sebanyak 9 soal.

\section{Deskripsi Data Hasil Penelitian}

a. Data Hasil Pretes

Pretes dilakukan untuk mengetahui kemampuan awal siswa sebelum diberikan materi. Dari hasil perhitungan nilai pretes diperoleh ratarata 38,83 untuk kelas eksperimen sedangkan kelas kontrol diperoleh 35,83

b. Data Hasil Postes

Postes dilakukan untuk mengetahui kemampuan awal siswa setelah dieberikan materi, dengan perolehan rata-rata kelas eksperimen 76,83 dan kelas kontrol 66,37.

\section{Analisis Data Hasil Penelitian}

a. Uji Normalitas 
Untuk uji normalitas jika $\mathrm{L}_{\text {hit }}<$ $\mathrm{L}_{\text {tabel }}$ maka data tersebut berdistribusi normal. Dengan menggunakan rumus Liliefors pada soal pretes dan postes baik kelas eksperimen dan kelas kontrol, dapat diketahui apakah data tersebut berdistribusi normal atau tidak.

\section{b. Uji Homogenitas}

Uji homogenitas ddilakukan dengan membandingkan nilai varians kedua data pretes dan kedua data postes dari kelas penelitian,dengan kriteria jika $\mathrm{F}_{\text {hit }}<\mathrm{F}_{\text {tab }}$ maka data tersebut homogen.

\section{c. Uji Hipotesis}

Setelah data memenuhi persyaratan normalitas dan homogenitas maka dilakukan pengujian hipotesis dimana hipotesis yag diajukan yaitu :

1. Hipotesis Kerja atau alternatif (Ha) : ada pengaruh model pembelajaran SAVI ( Somatis, Audiotori, Visual, Intelektual ) terhadap hasil belajar siswa kelas VII dalam pembelajaran lagu daerah setempat SMP Parulian 2 Medan.

2. Hipotesis nol ( $\mathrm{H} 0)$ : tidak ada pengaruh model pembelajaran SAVI ( Somatis, Audiotori, Visual, Intelektual) terhadap hasil belajar siswa kelas VII dalam pembelajaran lagu daerah setempat SMP Parulian 2 Medan.

Dari hasi perhitungan diperoleh $\mathrm{t}_{\text {hit }}=4,8132$ sedangkan $\mathrm{t}_{\text {tab }}$ 1,671 artinya $t_{\text {hit }}>t_{\text {tab }}$ maka dapat disimpulkan bahwa Ha diterima dan H0 ditolak artinya ada pengaruh model pembelajaran SAVI ( Somatis, Audiotori, Visual, Intelektual ) terhadapat hasil belajar siswak kelas VII dalm pembelajaran lagu daerah setempat SMP Parulian 2 Medan. 


\section{B.PEMBAHASAN}

PENELITIAN

Penelitian ini dilakukan dikelas

VII SMP Parulian 2 medan pada dua

kelas yang berbeda. Dimana kelas eksperimen diberikan pengajaran dengan model pembelajaran SAVI( somatis, audiotori, visual dan intelektual) sedangkan kelas kontrol diberikan pengajaran dengan model konvensional. Sebelum diberikan perlakuan pada kelas eksperimen dan kelas kontrol, maka dilakukan pretes. Setelah hasil pretes dilakukan, diperoleh pencapian tes hasil belajar siswa pada materi lagu daerah setempat pada kelas eksperimen adalah 38,83 dan pada kelas kontrol adalah 35,83 . Hasil pretes diatas menunjukan bahwa kedua kelas memiliki kemampuan awal yang hampir sama karena hanya terpaut sedikit saja pada rata-rata nilai kedua kelas. kemudian dilakukan perhitungan data yaitu dengan uji normalitas, homogenitas dan hipotessis. Untuk hasil postes diperoleh rata-rata tes hasil belajar siswa dalam pembelajaran lagu daerah setempat pada kelas eksperimen yang menggunakan model pembelajaran SAVI(Somatis, Audiotori, Visual dan Intelektual) adalah 76,83 sedangkan pada kelas kontrol dengan menggunakan model pembelajaran konvensional 66,37 . kemudian dilkakukan uji normalitas dan homogenitas, diperoleh nilai kedua kelas normal dan homogen. Selanjutnya, dilakukan uji t untuk nilai postes kedua kelas kedua kelas diperoleh $t_{\text {hitung }}=4,8132$ dan $t_{\text {tabel }}=$ 1,671. Karena $t_{\text {hitung }}>t_{\text {tabel }}$ maka Ha diterima sekaligus menolak Ho. Sehingga dapat disimpulkan bahwa terdapat perbedaan hasil belajar siswa yang diajar dengan model pembelajaran SAVI (Somatis,Audiotori, Visual dan 
Intelektual) dan model pembelajaran konvensional dalam pembelajaran lagu daerah setempat pada kelas VII SMP Parulian 2 Medan . berdasarkan hasil tersebut, terlihat bahwa hasil belajar siswa dengan menggunakan model pembelajaran SAVI (Somatis, Audiotori,Visual dan Intelektual) meningkat lebih besar dibandingkan nilai rata-rata hasil belajar siswa dengan menggunakan pembelajaran konvensiona.

\section{A. Kesimpulan}

Dari hasil penelitian yang dilakukan dapat diambil kesimpulan sebagai berikut :

1. Hasil belajar siswa dengan model pembelajaran SAVI (Somatis,Audiotori,Visual dan Intelektual ) dalam pembelajaran lagu daerah setempat kelas VII di SMP Parulian 2 medan tergolong baik dengan nilai ratarata 76,83 .

2. Ada pengaruh model pembelajaran SAVI (Somatis,Audiotori,Visual dan Intelektual) terhadap hasil belajar siswa le;as VII di SMP Parulian 2 Medan dengan hasil pengujian hipotesis $t_{\text {hitung }}>t_{\text {tabel }}$ yaitu $4,8132>1,671$ pada taraf $\alpha=0,05$ yang menyatakan menerimaHa sekaligus menolak Ho

3. Penerapan model pembelajaran SAVI (Somatis,Audiotori, Visual dan Intelektual) berpengaruh semakin baik terhadap hasil belajar siswa kelas VII dalam pembelajaran lagu daerah setempat di SMP Parulian 2 Medan. 


\section{B. Saran}

Berdasarkan pembahasan dan kesimpulan yang telah dikemukakan oleh penulis diatas, maka penulis mengajukan beberapa saran antara lain :

1. Kepada guru bidang studi Seni budaya dan keterampilan (SBK) agar dapat menarapkan model pembelajaran SAVI

(Somatis,Audiotori,Visual dan Intelektual) untuk meningkatkan hasil belajar siswa.

2. Bagi siswa agar dapat menjadikan model pembelajaran SAVI

(Somatis,Audiotori,Visual dan Intelektual) sebagai pengalaman belajar yang dapat meningkatkan hasil belajar
3. Bagi penulis (calon guru) dapat dijadikan pembelajaran SAVI (Somatis,Audiotori,Visual dan Intelektual) yang mampu meningkatkan hasil belajar siswa

\section{DAFTAR PUSTAKA}

Arikunto, Suharsimi. 2010. Prosedur Penelitian Suatu Pendekatan Praktik.Jakarta: Rineka Cipta

Apel, Daniel. 1960. The Harvad Brief Dictionary of Music. Cambridge, Massachusetts Harvad University Press

Indira. 2016. Pengaruh Model Pembelajaran Somatis, Audiotory, Visualization, Intelectually (SAVI) Terhadap Kemampuan Memproduksi Teks Negosiasi Oleh Siswa Kelas X SMA Swasta Dharmawangsa Medan Tahun Pembelajaran 2015/2016. Medan: UNIMED

Istarani. 2011. 58 Model Pembelajaran Inovatif. Medan: Media Persada

Jamalus. 1992. Pendidikan Kesenian 1 ( Musik). Jakarta : Departemen Pendidikan dan kebudayaan 
Jihad, Haris. 2013. Evaluasi Pembelajaran. Yogyakarta: Multi Presindo

Jauhari. 2011. Implementasi PAIKEM dari Behavioristik sampai Kontruktivistiksebuah pengembangan berbasis CTL (Contestual Teaching and Learnin). Jakarta:Prestasi Pustaka Raya

Istirani, Ridwan. 2015. 50 Tipe, Strategi dan Teknik Pembelajaran Kooperatif. Medan: Media Persada

Kitchenham. 2014. Population and Sampel Lecture 6 data collection Part one. Keele University. USA

Nainggolan, Rani. 2012. Pengaruh Model PIKEM Terhadap Hasil Belajar Musik Ansambel Rekorder Siswa Kelas VII SMP Negeri 18 Medan. Medan: UNIMED

Prestisa.

2013. http://journal.unnes.ac.id/sju/ine x.php/jsm di akses pada November 2013.

Purwanto. 2011. Evaluasi Hasil Belajar. Yogyakarta: Pustaka Belajar

Setyosari,Punaji.2010. Metode Penelitian Pendidikan dan pengembangan

Jakarta : Kencana

Silitonga. 2014. Teori Musik. Medan.Unimed Press

Sitorus. 2015. Pengaruh Model Pembelajaran SAVI ( Somatis, Audiotori,Visual, intelektual
) Terhadap Kemampuan Menulis Cerpen Kelas X SMA Negeri 1 Tanah Jawa Tahun Pembelajaran 2014/2015. Medan: UNIMED.

Trianto. 2011. Mendesain Model Pembelajaran Inovatif

Progresif. Jakarta: Kencana

Triyono. 2013. Metode Penelitian Pendidikan. Medan. Unimed Press

Tobing. 2013. Pengaruh Model Pembelajaran Somatis, Audiotori, Visual, Intelektual (SAVI) Terhadap Kemampuan Menulis Naskah Drama Siswa Kelas XI SMA Santo Yoseph Medan Tahun Ajaran 2013/2014. Medan: UNIMED

Simbolon. 2009. Penerapan Model Pembelajaran SAVI ( Somatis, Audiotori, Visual, Intelektual) Untuk Meningkatkan Hasil Belajar Siswa Pada Pokok Bahasan Pecahan di Kelas V SD Budi Luhur Medan. Medan: UNIMED

Situmorang. 2013. Penelitian Pendidikan. Medan: Unimed Press

Sugiyono. 2013. Metode Penelitian Pendidikan. Bandung: CV. Alfabeta

Yoyok, Siswandi. 2007. Pendidikan Seni Budaya. Jakarta: Yudhistira 